\title{
Physics Essay: Repulsionless Fusion by Neutron Absorption
}

\author{
David L. Selke ${ }^{1}$ \\ ${ }^{1}$ Mercury Systems, West Lafayette, Indiana, USA. \\ Correspondence: David L. Selke, Mercury Systems, West Lafayette, Indiana, USA. Tel: 254-423-1250. E-mail: \\ dselke@hotmail.com \\ Received: June 29, 2016 \\ Accepted: July 19, 2016 \\ Online Published: November 17, 2016 \\ doi:10.5539/apr.v8n6p30 \\ URL: http://dx.doi.org/10.5539/apr.v8n6p30
}

\begin{abstract}
It is possible to build Helium-4 from Hydrogen-1 by adding only neutrons. The key step is that Tritium decays to Helium-3; thus, a particle that entered the nucleus as a neutron becomes a proton. The need to overcome the mutual repulsion of positively charged nuclei is thus avoided. Given a cheap enough neutron source, this method promises fusion without Sun-like conditions.
\end{abstract}

Keywords: fusion, neutron, hydrogen, deuterium, tritium

\section{Introduction}

Alternative energy sources are the subject of intense interest because they promise to supply energy needs without the downsides of traditional sources. Fusion by neutron absorption as outlined above has the potential to be an easier path to fusion power production than other techniques which have not produced net power out despite over 50 years of investment. We leave to future work the examination of the neutron flux from different sources, the absorption cross section at different neutron energies, and other considerations, even though these may show the new technique to be infeasible.

\section{Neutron Sources}

One possible neutron source is nuclear waste. Another is a fission reactor, designed to be integrated with the fusion reactor so that some neutrons escaping, or within, the fission reactor are absorbed by the target Hydrogen and Helium of the fusion reactor.

\section{Constraints}

The about 12 year half-life of Tritium makes it desirable to remove the Tritium to storage while it decays, and reintroduce it to the fusion reactor as Helium-3. This requires an efficient and safe way of separating the Tritium from the other isotopes and storing it. Also, since the density of the target species will affect the chance of absorption in the target volume, higher pressures are desirable, however, safety and cost both require lower pressures. A reactor design finding an optimum of these considerations, as well as many other details, is desirable but beyond the scope of this work.

\section{Variations}

Because later absorptions release more energy, it is more efficient not to start with ${ }^{1} \mathrm{H}$. Of the overall change in binding energy going from ${ }^{1} \mathrm{H}$ to ${ }^{4} \mathrm{He}$, the absorption ${ }^{1} \mathrm{H}$ to ${ }^{2} \mathrm{H}$ releases $3.56 \times 10^{\wedge}-13 \mathrm{~J}$ or $7.86 \%$ of the overall energy, the absorption ${ }^{2} \mathrm{H}$ to ${ }^{3} \mathrm{H}$ releases $1.00 \times 10^{\wedge}-12 \mathrm{~J}$ or $22.1 \%$ of the overall energy, and the last absorption, ${ }^{3} \mathrm{He}$ to ${ }^{4} \mathrm{He}$, releases $3.30 \times 10^{\wedge}-12 \mathrm{~J}$ or $72.7 \%$ of the overall energy. Starting with Deuterium means more neutron absorptions are going to the more energy producing targets. If ${ }^{3} \mathrm{He}$ were abundant, it would be even more beneficial to start there. The percentages above add up to more than 100 because the overall reaction also includes the decay of Tritium to ${ }^{3} \mathrm{He}$, which is a reduction in binding energy.

\section{Conclusion}

A form of fusion for power was presented that may be more accessible than techniques tried to date. If it seems feasible after further analysis, a test reactor design should be proposed.

\section{Copyrights}

Copyright for this article is retained by the author(s), with first publication rights granted to the journal.

This is an open-access article distributed under the terms and conditions of the Creative Commons Attribution license (http://creativecommons.org/licenses/by/4.0/). 